\title{
Improvements of Deposited Interpolysilicon Dielectric Characteristics with RTP $\mathrm{N}_{2} \mathrm{O}$-Anneal
}

\author{
J. H. Klootwijk, Student Member, IEEE, M. H. H. Weusthof, \\ $\mathrm{H}$. van Kranenburg, P. H. Woerlee, and H. Wallinga, Member, IEEE
}

\begin{abstract}
Nitridation of deposited instead of thermally grown oxides was studied to form high-quality inter-polysilicon dielectric layers for nonvolatile memories. It was found that by optimizing the texture and morphology of the polysilicon layers, and by optimizing the post-dielectric deposition-anneal, very high-quality dielectric layers can be obtained. In this paper, it is shown that not only for deposited gate oxides, but also for deposited inter-polysilicon oxides, rapid thermal annealing leads to previously unpublished improved electrical characteristics, like high charge to breakdown $\left(\mathrm{Q}_{\mathrm{bd}} \approx 20 \mathrm{C} / \mathrm{cm}^{2}\right)$ and lower leakage currents. Moreover, the annealed dielectrics had less electron trapping when stressed.
\end{abstract}

\section{INTRODUCTION}

$\mathbf{T}$ HE main purpose of this research is to develop a deposited dielectric layer, which can be used as an interpolysilicon dielectric in nonvolatile memories. Conventional interpoly oxides are thermally grown (polyoxides) at very high temperatures. Thermal oxidation of silicon leads to roughening, which cause larger electric fields resulting in low-field tunneling processes and poor data retention. Recently [1], improvements have been shown with interpoly dielectrics thermally grown in pure $\mathrm{N}_{2} \mathrm{O}$. By using deposited instead of thermally grown dielectrics, even more reliable dielectrics can be grown since defects present in the silicon are not incorporated in the deposited layer, and the surface of the polysilicon layer is not roughened (no silicon consumption). This has already been shown for thicker dielectrics [2], but in this paper it is also proven for thinner dielectric layers $(\approx 25 \mathrm{~nm})$. Since as-deposited oxides are not as dense as thermally grown oxides and cause many traps, after-treatments like $\mathrm{N}_{2} \mathrm{O}$ annealing are needed to obtain desired electrical characteristics. In [3] and [4], it is shown that $\mathrm{N}_{2} \mathrm{O}$ annealing leads to large improvements of oxide layers, which is thought to derive from its incorporation of nitrogen at the oxide-silicon interface. In our application, i.e., the embedded vertical injection punchthrough-based metal oxide semiconductor (VIPMOS) EEPROM [5], erasing is performed by interpoly tunneling. Conflicting demands on the interpoly dielectric exist, namely good data retention (very low leakage currents) for low and moderate applied voltages and good tunneling characteristics for high voltages. This letter reports on deposited interpolysilicon dielectric layers, annealed

Manuscript received January 29, 1996; revised March 22, 1996. This work was supported by the Dutch Foundation for Fundamental Research on Matter (FOM) and the Netherlands Technology Foundation (STW).

The authors are with the MESA Research Institute, University of Twente, 7500 AE Enschede, The Netherlands.

Publisher Item Identifier S 0741-3106(96)05306-2. in $\mathrm{N}_{2} \mathrm{O}$ ambient, which can replace polyoxides as interpoly dielectric. It was found that this dielectric has very desirable qualities such as very high charge to breakdown $\left(Q_{b d}\right)$ and very low charge trapping. An extra advantage is the low thermal budget which is very attractive for embedded application. It was also remarkable that the $\mathrm{J}-\mathrm{E}$ characteristics had a reverse preference in polarity, such as a lower leakage current and a higher $Q_{b d}$ when the top electrode was positively biased, which also has been observed for thermally grown $\mathrm{N}_{2} \mathrm{O}$ oxides [1].

\section{EXPERIMENTS}

P-type wafers were thermally oxidized to a thickness of 100 $\mathrm{nm}$. Then a $300 \mathrm{~nm}$ silicon film (poly 1) with a very flat surface [6] was deposited by means of low-pressure chemical vapor deposition (LPCVD) at $550^{\circ} \mathrm{C}$ and implanted with phosphorus up to a dose of $8 \times 10^{15} \mathrm{~cm}^{-2}$ at $50 \mathrm{keV}$. The wafers were annealed for $30 \mathrm{~min}$ in $\mathrm{N}_{2}$ ambient to activate the dopant. Then a $25 \mathrm{~nm}$ thick dielectric layer was deposited, which consisted of HTO from $\mathrm{SiH}_{2} \mathrm{Cl}_{2}$ and $\mathrm{N}_{2} \mathrm{O}$ at $800^{\circ} \mathrm{C}$. This layer simultaneously serves as gate and interpoly dielectric. It was annealed in a rapid thermal processor in $\mathrm{N}_{2} \mathrm{O}$ ambient at $950^{\circ} \mathrm{C}$ for $20 \mathrm{~min}$. For comparison, dielectric layers without annealing were also processed. A second silicon layer (poly 2) of $300 \mathrm{~nm}$ was then deposited by means of LPCVD at $625^{\circ} \mathrm{C}$. This film was implanted with arsenic up to a dose of $6 \times 10^{15}$ $\mathrm{cm}^{-2}$ at $100 \mathrm{keV}$. After defining poly 2, all samples received a $200 \mathrm{~nm}$ thick CVD oxide as a passivation layer. Contact holes were opened and $\mathrm{Al}$ was deposited and patterned to form the capacitor structures. Finally, all devices were sintered at $400^{\circ} \mathrm{C}$ for $30 \mathrm{~min}$ in wet $\mathrm{N}_{2}$ ambient.

\section{RESUlTS AND DISCUSSION}

Due to the rapid thermal $\mathrm{N}_{2} \mathrm{O}$ annealing, the dielectric thickness of the interpoly dielectrics increased by about $5 \%$ to $260 \AA$ (measured by ellipsometry). Typical J-E curves of $\mathrm{N}_{2} \mathrm{O}$ annealed dielectrics are shown in Fig. 1 along with those of as-deposited dielectric layers. It can be seen that the $\mathrm{N}_{2} \mathrm{O}$ annealed dielectrics conducted a lower leakage current and started conducting at higher voltages than the as-deposited dielectric when the top electrode (poly 2) was positively biased. Also, a higher breakdown field was observed for the annealed dielectrics.

Fig. 2 shows typical $Q_{b d}$ plots of the samples, from which also the trapping behavior can be determined. The capacitor area was $1 \times 10^{-4} \mathrm{~cm}^{2}$ and the stress condition was 


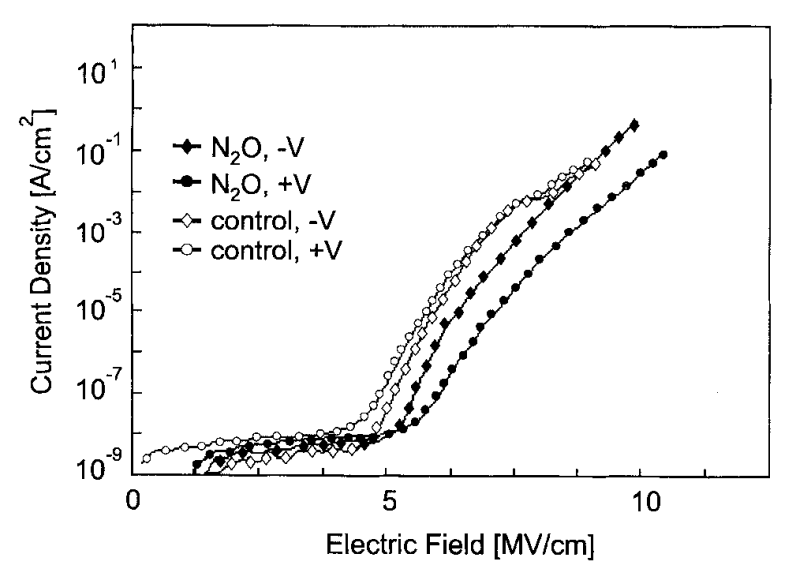

Fig. 1. Typical J-E characteristics of as-deposited and $\mathrm{N}_{2} \mathrm{O}$ annealed interpolysilicon dielectric layers under positive and negative applied voltages. The dielectric thickness of all capacitor structures was $25 \mathrm{~nm}$.

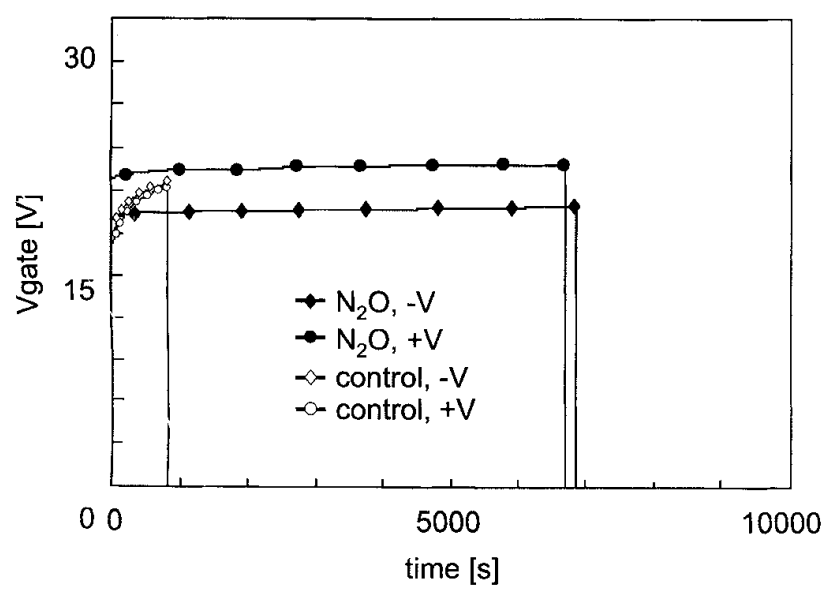

Fig. 2. Typical $Q_{B D}$ characteristics of the as-deposited and $\mathrm{N}_{2} \mathrm{O}$ annealed interpolysilicon dielectric layers under positive and negative constant current stress of $2.5 \mathrm{~mA} / \mathrm{cm}^{2}$. The area of the capacitors was $1 \times 10^{-4} \mathrm{~cm}^{2}$.

$2.5 \mathrm{~mA} / \mathrm{cm}^{2}$ constant current injection for both positive and negative bias. It can be seen that the $\mathrm{N}_{2} \mathrm{O}$ annealed dielectrics had a much higher $Q_{b d}$ and a much smaller voltage shift $(\Delta V)$ than the as-deposited dielectric. This implies that the $\mathrm{N}_{2} \mathrm{O}$ annealed dielectric trapped fewer electrons. The $\mathrm{N}_{2} \mathrm{O}$ annealed dielectric had slightly different voltage shifts for positive and negative bias, which is ascribed to the nitrogen peak (observed by means of Auger measurements) at the $\mathrm{Si}-\mathrm{SiO}_{2}$ interface. However, when we look at the as-deposited dielectric layers, $Q_{B D}$ results are still very attractive as interpolysilicon dielectric in comparison with interpolysilicon dielectric layers, which were directly grown in $\mathrm{N}_{2} \mathrm{O}$ ambient [1].

Fig. 3 shows the Weibull charge to breakdown plot for 100 capacitors under $2.5 \mathrm{~mA} / \mathrm{cm}^{2}$ stress. It is shown that the $\mathrm{N}_{2} \mathrm{O}$ annealed dielectric has the largest $Q_{b d}$ with a very narrow distribution. This improvement is due to the reduced electron trapping (as was shown in Fig. 2, where a much lower

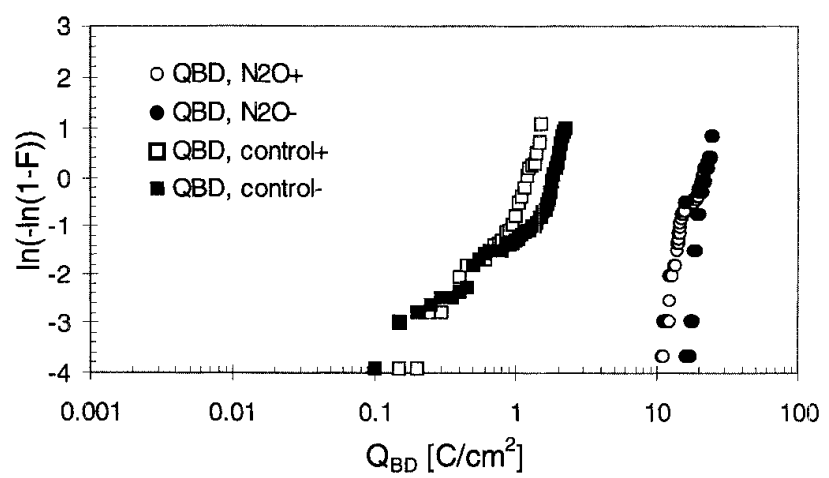

Fig. 3. Typical Weibull plots of the $Q_{B D}$ (charge to breakdown) for the as-deposited and $\mathrm{N}_{2} \mathrm{O}$ annealed dielectric layers under positive and negative stress. A constant current density of $2.5 \mathrm{~mA} / \mathrm{cm}^{2}$ was applied to capacitors with an area of $1 \times 10^{-4} \mathrm{~cm}^{-2}$.

$\Delta V$ occurred during constant current stress). The as-deposited layers have a broader distribution. The reverse preference in polarity of the $\mathrm{J}-\mathrm{E}$ characteristics between the $\mathrm{N}_{2} \mathrm{O}$ annealed and as-deposited dielectric layer is also remarkable.

\section{CONCLUSION}

In conclusion, the above results show that deposited oxides with additional $\mathrm{N}_{2} \mathrm{O}$ anneal are a very attractive alternative for replacing polyoxides as interpoly dielectric for non volatile memory application. Due to the low thermal budget they are very attractive for embedded applications. It has desirable low leakage currents and high $E_{b d}$ for top electrode electron injection, reduced electron trapping (due to the nitrogen incorporation) and a much larger charge to breakdown $\left(Q_{b d}\right)$ than the as deposited variant.

\section{ACKNOWLEDGMENT}

The authors would like to thank Dr. C. Cobianu for helpful discussions. The MESA clean room staff is kindly acknowledged for their support.

\section{REFERENCES}

[1] C. S. Lai, T. F. Lei, and C. L. Lee, "The electrical characteristics of polysilicon oxide grown in pure $\mathrm{N}_{2} \mathrm{O}$," IEEE Electron Device Lett., vol. 16, pp. 385-387, 1995.

[2] C. Cobianu, O. Popa, and D. Dascalu, "On the electrical conduction in the interpolysilicon dielectric layers," IEEE Electron Device Lett., vol. 14, pp. 213-215, 1993.

[3] J. Ahn, W. Ting, and D. L. Kwong, "Furnace nitridation of thermal $\mathrm{SiO}_{2}$ in pure $\mathrm{N}_{2} \mathrm{O}$ ambient for ULSI MOS application," IEEE Electron. Device Lett., vol. 13, p. 117, 1992.

[4] H. Hwang, W. Ting, D. L. Kwong, and J. Lee, "Electrical and reliability characteristics of the ultrathin oxynitride prepared by rapid thermal processing ins $\mathrm{N}_{2} \mathrm{O}$." IEDM Tech. Dig., p. 421, 1990.

[5] R. C. M. Wijburg, G. J. Hemink, J. Middelhoek, H. Wallinga, and A. J. Mouthaan, "VIPMOS - A novel buried injector structure for EPROM application," IEEE Trans. Electron Devices, vol. 39, no. 1, p. 111, 1991.

[6] J. H. Klootwijk, H. Van Kranenburg, C. Cobianu, V. Petrescu, P. H. Woerlee, and $\mathrm{H}$. Wallinga, "An intensive study of LPCVD silicon morphology and texture for non volatile memory application," in Proc. 25th European Solid State Dev. Res. Conf., 1995, pp. 383-386. 